\title{
Nasal high flow delivered within the helmet: a new non-invasive respiratory support
}

Tommaso Mauri ${ }^{1,2}$, Elena Spinelli ${ }^{2}$, Massimiliano Mariani ${ }^{1}$, Amedeo Guzzardella ${ }^{1}$, Chiara

Del Prete ${ }^{1}$, Eleonora Carlesso ${ }^{1}$, Donatella Tortolani ${ }^{3}$, Paola Tagliabue ${ }^{2}$, Antonio Pesenti $^{1,2}$, Giacomo Grasselli ${ }^{1,2}$.

1. Department of Pathophysiology and Transplantation, University of Milan, Italy

2. Department of Anesthesia, Critical Care and Emergency, Fondazione IRCCS Ca' Granda Ospedale Maggiore Policlinico, Milan, Italy

3. Department of Morphology, Surgery and Experimental Medicine, Section of Anesthesia and Intensive Care, University of Ferrara, Italy

\section{Corresponding author:}

\section{Antonio Pesenti MD}

Professor of Anesthesia and Critical Care, Department of Pathophysiology and Transplantation, University of Milan

Director, Department of Anesthesia, Critical Care and Emergency, Fondazione IRCCS Ca' Granda Ospedale Maggiore Policlinico

Via F. Sforza 35, 20122 Milan, Italy

Tel.: +39-02-55033232

Fax: $+39-02-55033230$

E-mail: antonio.pesenti@unimi.it

Author's contributions. TM, ES, GG, AP conceived and designed the study. TM, ES, MM, AG, CDP, EC, DT, PT participated to acquisition and analysis of data for the study. TM and 
ES drafted the work. All authors collaborated to interpretation of data, revising the work critically for important intellectual content and approved the version to be published. TM and AP agreed to be accountable for all aspects of the work in ensuring that questions related to the accuracy or integrity of any part of the work are appropriately investigated and resolved.

Sources of support. The present study was supported in part by institutional funding (Ricerca corrente 2018 - "Rimozione extracorporeal di anidride carbonica $\left(\mathrm{CO}_{2}\right)$ e modulazione della ventilazione spontanea in pazienti con insufficienza respiratoria acuta (sindrome da distress respiratorio, ARDS) e acuta su cronico (broncopneumopatia cronico ostruttiva, COPD)") of the Department of Anesthesia, Critical Care and Emergency, Fondazione IRCCS Ca' Granda Ospedale Maggiore Policlinico, Milan, Italy.

Running head. Nasal high flow within the helmet.

Descriptor number. 4.08 Mechanical Ventilation: Physiology \& Pathophysiology

Total word count. 1217

Keywords. High flow nasal cannula, helmet, non-invasive ventilation, physiology, positive end-expiratory pressure (PEEP). 


\section{INTRODUCTION}

Physiologic effects of high flow nasal cannula (HFNC) include $\mathrm{CO}_{2}$ washout from the upper airways, reduction of the work of breathing (1-2) and generation of positive end-expiratory pressure (PEEP) (3-4). However, the PEEP level obtained by HFNC is relatively low (i.e., 2-5 $\mathrm{cmH}_{2} \mathrm{O}$ ), very difficult to measure in clinical practice and predictably unstable (i.e., PEEP may vary with patient's mouth opening) (3-6). The HELMET is an interface designed to deliver non-invasive positive pressure ventilation or continuous positive airway pressure (CPAP) in a more comfortable and effective way than facial masks (7-8). The PEEP level generated in the HELMET is in the $5-15 \mathrm{cmH}_{2} \mathrm{O}$ range, easily measurable at the bedside and independent from mouth opening. However, previous studies showed that low levels of $\mathrm{CO}_{2}$ can accumulate within the helmet, potentially leading to $\mathrm{CO}_{2}$ re-breathing and additional workload for the patient (7-8). In summary, with HFNC, flow is set, and pressure is variable, while with HELMET CPAP, pressure is set and flow is variable.

We reasoned that a coupled HFNC+HELMET system could combine the positive effects of each support (i.e., $\mathrm{CO}_{2}$ washout and reduced re-breathing + high measurable stable PEEP) and herein report preliminary data on healthy volunteers.

\section{METHODS}

The Ethical Committee of the Fondazione IRCCS Ca' Granda Ospedale Maggiore Policlinico, Milan, Italy, approved the study (reference number: 431/2016) and informed consent was obtained. Healthy volunteers were recruited from medical students and anesthesia residents from our hospital unaware of the study design and hypothesis (e.g., none of the authors of the present article acted as volunteer and none of the students or residents enrolled were involved in ventilation-related clinical research activities). 
A custom-made system to deliver HFNC within a sealed HELMET connected to a water PEEP valve was developed (HFNC flow $50 \mathrm{l} / \mathrm{min}$, temperature $31^{\circ} \mathrm{C}$ and external PEEP 8 $\left.\mathrm{cmH}_{2} \mathrm{O}\right):$ HFNC $\left(\mathrm{AIRVO}^{\mathrm{TM}}\right.$ 2, Fisher \& Paykel Healthcare, Auckland, New Zealand) was passed through an existing port in the lower part of a commercially available HELMET (StarMed CaStar Up, Intersurgical Ltd. Wokingham, UK) and sealed by an appropriate rubber gasket; the standard inlet port of the HELMET was closed and sealed, while respiratory tubing connected the expiratory port to a water PEEP valve.

Five healthy volunteers (study no. 1) were kept in semi-recumbent position and a small-bore plastic tube was positioned through a sealed hole inside the HFNC+HELMET system, close to the mouth. Waveforms of airway pressure (Paw) inside the HFNC+HELMET were recorded on a computer for subsequent analysis by dedicated system (Colligo, Elekton, Milan, Italy). $\mathrm{FiO}_{2}$ was 0.30 , flow $50 \mathrm{l} / \mathrm{min}$ and temperature $31^{\circ} \mathrm{C}$. Each subject underwent three study phases (random order, 15 minutes) at external PEEP of 3, 5 and $8 \mathrm{cmH}_{2} \mathrm{O}$. Towards the end, we measured vital signs, comfort (by a numeric 0-10 scale), mean Paw ( $\left.\mathrm{Paw}_{\mathrm{m}}\right)$ and the average Paw excursion ( $\triangle \mathrm{Paw})$ during the respiratory cycle.

Eight healthy volunteers (study no. 2) were kept in semi-recumbent position and a small-bore plastic tube was advanced through a nostril to the hypopharynx. Waveforms of the $\mathrm{CO}_{2}$ tension were recorded through this tube for 2-3 minutes at the end of each study phase (ORIDION Capnostream ${ }^{\mathrm{TM}}$ C35 Medtronic, Minneapolis, MN) while EIT data (PulmoVista ${ }^{\circledR}$ 500, Dräger Medical GmbH, Lübeck, Germany) were continuously recorded. Each subject underwent the following phases (random order, 15 minutes, $\mathrm{FiO}_{2} 0.30$ ):

- Standard HFNC at $50 \mathrm{l} / \mathrm{min}$ and $31{ }^{\circ} \mathrm{C}$;

- Standard HELMET CPAP, with flow 50 L/min, no active humidification and external PEEP $8 \mathrm{cmH}_{2} \mathrm{O}$ 
- Combined HFNC+HELMET system, flow $50 \mathrm{l} / \mathrm{min}$, temperature $31{ }^{\circ} \mathrm{C}$ and external PEEP 8 $\mathrm{cmH}_{2} \mathrm{O}$.

Towards the end, we recorded vital signs, comfort, the average inspiratory and expiratory $\mathrm{CO}_{2}$ levels $\left(\mathrm{PiCO}_{2}\right.$ and $\left.\mathrm{PeCO}_{2}\right)$ and, from EIT, global, non-dependent and dependent tidal volumes $\left(\mathrm{V}_{\mathrm{T}, \text { glob }}, \mathrm{V}_{\mathrm{T} \text {, non-dep }}\right.$ and $\left.\mathrm{V}_{\mathrm{T}, \text { dep }}\right)$; ventilation heterogeneity $\left(\mathrm{Vt}_{\text {non-dep }} / \mathrm{Vt}_{\text {dep }}\right.$ ratio); minute ventilation (MV); corrected minute ventilation $\left(\mathrm{MV}_{\text {corr }}=\mathrm{MV}^{*}\left[\right.\right.$ actual $\left.\left.\mathrm{PeCO}_{2} / 40 \mathrm{mmHg}\right]\right)$;

global and regional changes in end-expiratory lung impedance $\left(\triangle \mathrm{EELI}_{\mathrm{glob}}, \Delta \mathrm{EELI} \mathrm{I}_{\text {non-dep }}\right.$ and $\left.\Delta \mathrm{EELI}_{\mathrm{dep}}\right)(3-4)$

Study sample size was chosen based on previous studies $(7,8)$. Given the small samples size, differences between variables across study phases were tested by by one-way repeated measures ANOVA on ranks. Tukey test was used for post-hoc correction (SigmaPlot 11.0, Systat Software Inc., San Jose, CA).

\section{RESULTS}

Paw $_{\mathrm{m}}$ within the HFNC+HELMET system at three levels of external PEEP $(3,5$ and 8 $\mathrm{cmH}_{2} \mathrm{O}$ ) closely corresponded to the set PEEP level and Paw oscillations during the respiratory cycle were very small (Table 1), indicating that the HFNC+HELMET system effectively provides high, stable and measurable PEEP. All the subjects tolerated well the HFNC+HELMET system at increasing PEEP levels (Table 1).

$\mathrm{PiCO}_{2}$ measured at the hypopharynx level was significantly higher during the standard HELMET phase than with HFNC and the HFNC+HELMET system, which had similar very low values (Table 2). Respiratory rate and minute ventilation were significantly higher during the standard HELMET phase in comparison with HFNC and HFNC+HELMET, which were lower and similar (Table 2). $\mathrm{PeCO}_{2}$ (i.e., the closest surrogate for arterial $\mathrm{CO}_{2}$ tension in this study) wasn't increased during HFNC and HFNC+HELMET in comparison to standard 
HELMET despite reduced ventilation, thus yielding significantly reduced $\mathrm{VM}_{\text {corr }}$ (Table 2). The decrease in minute ventilation was mainly driven by a reduction in respiratory rate, while global and regional Vt did not change significantly. End-expiratory lung volume, as assessed by $\triangle$ EELI, significantly increased during HELMET and HFNC+HELMET phases, globally and in the dependent and non-dependent lung regions, suggesting a homogenous distribution typical of healthy subjects. The increase in lung volume was similar between standard HELMET and HFNC+HELMET (Table 2), once again indicating comparable PEEP level delivered by the two systems. Vital parameters and comfort remained stable with all the three modes of respiratory support (Table 2).

\section{DISCUSSION}

The novel HFNC+HELMET system, delivering nasal high flow within a sealed helmet connected to a PEEP valve, provides a clinically relevant, measurable and stable PEEP. Moreover, the HFNC+HELMET system grants effective $\mathrm{CO}_{2}$ washout from upper airways, with negligible $\mathrm{CO}_{2}$ re-breathing and enhanced $\mathrm{CO}_{2}$ clearance.

Previous studies showed that increasing lung volume by standard HELMET (9) and lowering dead space by HFNC (10) might reduce intubation rate of acute hypoxemic respiratory failure (AHRF) patients. Thus, the present studies generate the hypothesis that the combined HFNC+HELMET system may enhance our ability to avoid intubation and all the attendant risks of invasive mechanical ventilation in AHRF.

The present studies have relevant limitations: they were performed in a small sample of healthy volunteers and their results may not apply to AHRF patients; key physiologic variables like inspiratory effort and transpulmonary pressure were not investigated; study phases were short and longer-term effects could differ (e.g., patients' comfort within the new HFNC+HELMET might be poorer than with standard HFNC limiting long-term application); 
in the clinical setting, HFNC+HELMET may mask signs of deteriorating respiratory function and delay intubation, yielding poorer clinical outcomes; previous studies $(7,8)$ showed that, when the fresh gas flow is set above $30 \mathrm{l} / \mathrm{min}, \mathrm{CO}_{2}$ rebreathing within the HELMET CPAP system might be negligible and the new HFNC+HELMET system less useful.

In conclusion, the combination of HFNC+HELMET might present additive physiologic effects, potentially representing a new non-invasive respiratory support. Further studies in AHRF patients are needed to replicate the present findings and to assess the effects of $\mathrm{HFNC}+\mathrm{HELMET}$ on arterial $\mathrm{CO}_{2}$ tension (in hypercapnic patients) and on recruitment, oxygenation and the respiratory drive (in hypoxemic patients). 


\section{REFERENCES}

1. Papazian L, Corley A, Hess D, Fraser JF, Frat JP, Guitton C, Jaber S, Maggiore SM, Nava S, Rello J, Ricard JD, Stephan F, Trisolini R, Azoulay E. Use of high-flow nasal cannula oxygenation in ICU adults: a narrative review. Intensive Care Med 2016;42(9):13361349.

2. Moller W, Celik G, Feng S, Bartenstein P, Meyer G, Oliver E, Schmid O, Tatkov S. Nasal high flow clears anatomical dead space in upper airway models. J Appl Physiol (1985) $2015 ; 118: 1525-1532$.

3. Mauri T, Turrini C, Eronia N, Grasselli G, Volta CA, Bellani G, Pesenti A. Physiologic effects of high-flow nasal cannula in acute hypoxemic respiratory failure. Am $J$ Respir Crit Care Med 2017;195:1207-1215.

4. Mauri T, Alban L, Turrini C, Cambiaghi B, Carlesso E, Taccone P, Bottino N, Lissoni A, Spadaro S, Volta CA, et al. Optimum support by high-flow nasal cannula in acute hypoxemic respiratory failure: Effects of increasing flow rates. Intensive Care Med 2017;43:1453-1463.

5. Mundel T, Feng S, Tatkov S, Schneider H. Mechanisms of nasal high flow on ventilation during wakefulness and sleep. $J$ Appl Physiol (1985) 2013;114:1058-1065.

6. Parke RL, McGuinness SP. Pressures delivered by nasal high flow oxygen during all phases of the respiratory cycle. Respir Care 2013;58:1621-1624.

7. Patroniti N, Foti G, Manfio A, Coppo A, Bellani G, Pesenti A. Head helmet versus face mask for non-invasive continuous positive airway pressure: A physiological study. Intensive Care Med 2003;29:1680-1687.

8. Taccone P, Hess D, Caironi P, Bigatello LM. Continuous positive airway pressure delivered with a "Helmet": Effects on carbon dioxide rebreathing. Crit Care Med 2004;32:2090-2096. 
9. Patel BK, Wolfe KS, Pohlman AS, Hall JB, Kress JP. Effect of noninvasive ventilation delivered by helmet vs face mask on the rate of endotracheal intubation in patients with Acute Respiratory Distress Syndrome: a randomized clinical trial. JAMA $2016 ; 315: 2435-2441$.

10. Frat JP, Thille AW, Mercat A, Girault C, Ragot S, Perbet S, Prat G, Boulain T, Morawiec E, Cottereau A, et al. High-flow oxygen through nasal cannula in acute hypoxemic respiratory failure. $N$ Engl $J$ Med 2015;372:2185-2196. 


\section{TABLES}

Table 1. Results from study no. 1 (see text for details): variables measured at 3 different set PEEP levels during support by the novel HFNC+HELMET system.

\begin{tabular}{|c|c|c|c|c|}
\hline Variable & $\begin{array}{c}\text { Set PEEP: } \\
3 \underset{n=5}{\mathrm{cmH}_{2} \mathrm{O}} \\
\end{array}$ & $\begin{array}{c}\text { Set PEEP: } \\
5 \mathrm{cmH}_{2} \mathrm{O} \\
n=5\end{array}$ & $\begin{array}{c}\text { Set PEEP: } \\
8 \mathrm{cmH}_{2} \mathrm{O} \\
n=5\end{array}$ & P-value \\
\hline $\mathrm{Paw}_{\mathrm{m}}, \mathrm{cmH}_{2} \mathrm{O}$ & $3.2[2.8-3.5]$ & $5.4[5.4-6.0]$ & $8.2[8.1-8.5]^{*}$ & $<0.001$ \\
\hline$\Delta \mathrm{Paw}, \mathrm{cmH}_{2} \mathrm{O}$ & $1.0[0.7-1.1]$ & $0.8[0.6-1.1]$ & $0.7[0.4-1.0]$ & 0.522 \\
\hline $\mathrm{SpO}_{2}, \%$ & $100[99-100]$ & 99 [99-100] & 99 [99-100] & 0.954 \\
\hline RR, breaths/min & $15.0[11.5-18.0]$ & $12.0[9.0-14.5]$ & $12.0[5.0-16.0]$ & 0.182 \\
\hline HR, bpm & 60 [51-67] & $60[52-73]$ & 63 [53-68] & 0.124 \\
\hline SBP, mmHg & $131.0[123-150]$ & $138.0[124-145]$ & $141.0[127-155]$ & 0.367 \\
\hline DBP, mmHg & 87.0 [76-93] & 92.0 [83-93] & 93.0 [83-97] & 0.182 \\
\hline Comfort (0-10), n & $7.0[7.0-9.0]$ & $6.0[5.0-9.0]$ & $7.0[5.5-8.5]$ & 0.367 \\
\hline
\end{tabular}

Variables are expressed as median and interquartile range [IQR]. P-values refer to Friedman Repeated Measures Analysis of Variance on Ranks. Post-Hoc Multiple Comparison Procedures (Tukey Test on ranks):

$* \mathrm{p}<0.001$ vs. PEEP $3 \mathrm{cmH}_{2} \mathrm{O}$

PEEP: positive end expiratory pressure; $\mathrm{Paw}_{\mathrm{m}}$ : mean airway pressure inside the HFNC+HELMET system; $\triangle$ Paw: average Paw excursion during the respiratory cycle; SpO2: peripheral arterial $\mathrm{O}_{2}$ saturation; RR: respiratory rate; HR: heart rate; SBP: systolic blood pressure; DBP: diastolic blood pressure. 
Table 2. Results from study no. 2 (see text for details): effects of the 3 non-invasive respiratory support systems on vital signs, ventilation, $\mathrm{CO}_{2}$ clearance, and lung volumes.

\begin{tabular}{|c|c|c|c|c|}
\hline Variable & $\begin{array}{c}\text { HFNC } \\
\mathbf{n}=\mathbf{8}\end{array}$ & $\begin{array}{l}\text { HELMET } \\
\mathbf{n}=\mathbf{8}\end{array}$ & $\begin{array}{c}\text { HFNC+ } \\
\text { HELMET } \\
\mathbf{n}=\mathbf{8}\end{array}$ & P-value \\
\hline $\mathrm{SpO}_{2}, \%$ & 100 [99-100] & 100 [99-100] & 100 [99-100] & 1.000 \\
\hline RR, breaths/min & $8.5[6.3-10.0]$ & $14.5[9.0-17.0]^{*}$ & $10.0[5.5-11.8] \dagger$ & 0.010 \\
\hline HR, bpm & $67[62-73]$ & $69[64-80]$ & $70[68-76]$ & 0.355 \\
\hline SBP, mmHg & $117[107-124]$ & $123[113-131]^{*}$ & $127[113-131]^{*}$ & $<0.001$ \\
\hline DBP, mmHg & 74 [73-79] & 79 [74-82] & $77[74-82]$ & 0.531 \\
\hline Comfort (0-10), n & $8.0[6.0-8.0]$ & $8.0[6.0-8.0]$ & $7.0[4.5-8.0]$ & 0.654 \\
\hline $\mathrm{PiCO}_{2}, \mathrm{mmHg}$ & $0.01[0.00-0.12]$ & $1.72[1.46-3.92]^{*}$ & $0.06[0.00-0.79] \dagger$ & $<0.001$ \\
\hline $\mathrm{PeCO}_{2}, \mathrm{mmHg}$ & $34.0[26.3-38.5]$ & $36.7[35.2-37.9]$ & $33.5[26.5-39.3]$ & 1.000 \\
\hline $\mathrm{Vt}_{\text {glob}}$, a.u. & 4152 [3625-7207] & 3558 [3111-7036] & 4689 [3054-6843] & 0.654 \\
\hline $\begin{array}{l}\mathrm{Vt}_{\text {glob, }} \text { change vs. } \\
\text { HFNC phase, \% }\end{array}$ & Ref. & $-8.7[(-40.2)-32.9]$ & $15.6[(-28.4)-77.6]$ & 0.654 \\
\hline$V t_{\text {non-dep }}, a . u$. & $2036[1537-3881]$ & $1735[1587-4208]$ & 1670 [1513-4799] & 0.794 \\
\hline $\begin{array}{l}\mathrm{Vt}_{\text {non-dep }} \text {, change vs. } \\
\text { HFNC phase, } \%\end{array}$ & Ref. & $-12.6[(-46.8)-35.1]$ & $-8.5[(-36.8)-79.3]$ & 0.794 \\
\hline$V t_{\text {dep }}$, a.u. & 2388 [1675-2922] & $1894[1670-2841]$ & $2463[1553-3558]$ & 0.355 \\
\hline $\begin{array}{l}V t_{\text {dep }}, \text { change vs. } \\
\text { HFNC phase, } \%\end{array}$ & Ref. & $-5.6[(-32.9)-30.4]$ & $12.8[(-28.1)-75.3]$ & 0.355 \\
\hline $\mathrm{Vt}_{\text {non-dep }} / \mathrm{Vt}_{\text {dep }}$ ratio & $1.2[0.8-1.3]$ & $1.0[0.7-1.6]$ & $1.0[0.6-1.4]$ & 0.531 \\
\hline MV, a.u. & $\begin{array}{c}36049 \\
{[32170-44372]}\end{array}$ & $\begin{array}{c}54344 \\
{[43061-61904]}\end{array}$ & $\begin{array}{c}39241 \\
{[32071-44941]}\end{array}$ & 0.038 \\
\hline $\begin{array}{l}\text { MV, change vs. } \\
\text { HFNC phase, \% }\end{array}$ & Ref. & $46[23-85]$ & $3[(-20)-22]$ & 0.038 \\
\hline MV $_{\text {corr, }}$ a.u. & $\begin{array}{c}31941 \\
{[28980-35343]} \\
\end{array}$ & $\begin{array}{c}47723 \\
{[41033-56663]} \\
\end{array}$ & $\begin{array}{c}30326 \\
{[26318-36169] \dagger}\end{array}$ & 0.005 \\
\hline $\begin{array}{l}M_{\text {corr }} \text { change vs. } \\
\text { HFNC phase, } \%\end{array}$ & Ref. & 58 [20-98] & $-7[(-12)-25] \dagger$ & 0.005 \\
\hline$\Delta$ EELI $_{\text {glob }}$, a.u. & Ref. & $5682[2821-8222]^{*}$ & $5959[4793-8414]^{*}$ & $<0.001$ \\
\hline$\Delta$ EELI $_{\text {non-dep }}$, a.u. & Ref. & 3905 [1933-4809]* & 3938 [3323-5769]* & $<0.001$ \\
\hline$\Delta E_{E L L I}$ dep, a.u. & Ref. & $1774[1217-3412]^{*}$ & $2213[1476-3065]^{*}$ & 0.008 \\
\hline
\end{tabular}

Variables are expressed as median and interquartile range [IQR]. P-values refer to Friedman Repeated Measures Analysis of Variance on Ranks. Post-Hoc Multiple Comparison Procedures (Tukey Test on ranks):

$* \mathrm{p}<0.05$ vs. HFNC;

$\dagger \mathrm{p}<0.05$ vs. HELMET.

HFNC: standard high flow nasal cannula with 50 1/min flow; HELMET: standard HELMET CPAP system with fresh inlet gas flow of $50 \mathrm{l} / \mathrm{min}$ and connected to water valve with PEEP 8 $\mathrm{cmH}_{2} \mathrm{O}$; HFNC+HELMET: novel system with HFNC at $50 \mathrm{l} / \mathrm{min}$ delivered inside sealed HELMET connected to water valve with PEEP $8 \mathrm{cmH}_{2} \mathrm{O}$; SpO2: peripheral arterial $\mathrm{O}_{2}$ 
saturation; RR: respiratory rate; HR: heart rate; SBP: systolic blood pressure; DBP: diastolic blood pressure; $\mathrm{PiCO}_{2}$ : inspiratory $\mathrm{CO}_{2}$ pressure; $\mathrm{PeCO}_{2}$ : expiratory $\mathrm{CO}_{2}$ pressure; $\mathrm{Vt}_{\mathrm{glob}}$ : tidal volume distending the respiratory system meacured by EIT; a.u.: arbitrary units of impedance change; $\mathrm{Vt}_{\text {non-dep }}$ : tidal volume distending the non-dependent region; Vtdep: tidal volume distending the dependent region; $\mathrm{MV}$ : minute ventilation; $\mathrm{MV}_{\text {corr }}$ : corrected minute ventilation; $\triangle E E L I_{\text {glob }}$ : change in end-expiratory lung impedance from the HFNC baseline phase; $\triangle \mathrm{EELI}_{\text {non-dep }}$ : change in end-expiratory lung impedance of the non-dependent region; $\triangle \mathrm{EELI}_{\mathrm{dep}}$ : change in end-expiratory lung impedance of the dependent region; 